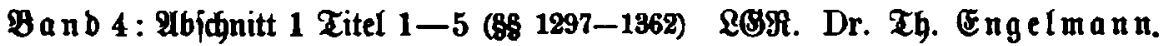
Titel 6 (\$8 1363-1563) . . . . Beh. M. Dr. J.b. Sta ubinger. Titel 7 unb 8 (\$8 1564-1588). . LBR. Dr. Th. Engelmann.

Band 5 शbidnitt 2 und 3 (\$8 1589-1921) . 2\&9. Dr. Th. Engelmann. Band 6 RA. Dr. F. Serzfelber. O\&\&. $\$$. Bagner.

Die rebattionelle Reitung bes Bejamtmerfes führte bis zu feinem im f̧ebruar 1902 erfolgten Tobe Beb. $\Re$. $\mathfrak{b}$. Staubinger, von ba ab ERAs. Sober.

Mrünđen, im MRärz 1903.

\title{
Sit Eertusfgetber.
}

\section{Dorwort jur 2. Iluflage.}

Die Biele unb Zmecte ber neuen 2 uflage geben über bie ber erften erbeblid Ginaus. Währenb ę̧ jiđ bei biefer vieffađ nur um marfante Darftellung ber Brunbzüge bes Bejekez hanbeln tonnte, mußste nunmehr zu ben inzmifisen in getwaltiger $\mathfrak{A} \mathfrak{n} z a \mathfrak{h l}$ aufgetaudbten Einzelfragent Stellung genommen werben. Dẩ bie erweiterte 2 lufgabe eine böllige Umgeftaltung einzelner Teile erforberlich madte, wirb aud bei flüdtiger Bergleiđung ber beiben 2 uflagen niळt überieben merben tönnen.

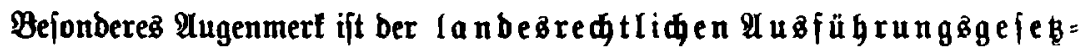

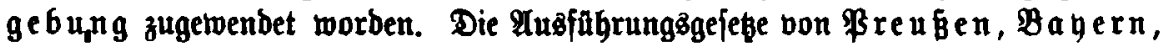

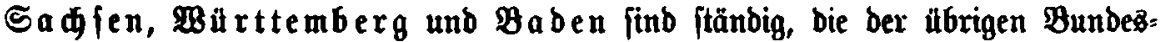

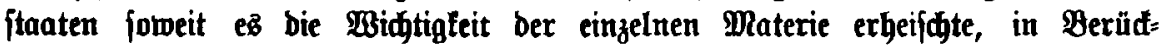

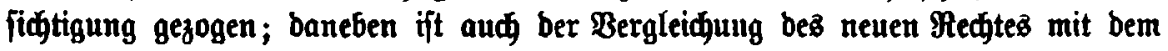

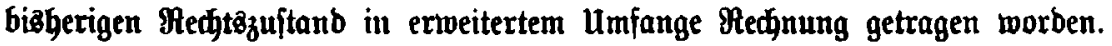

Der Name bes inzwificen berftorbenen Serauzgebers ber 1. Auflage, (Bebeimrats von Staubinger, foll aud fernergin bem $2 B e r f e$ erbalten bleiben. Bon bent in erfter Pluflage burd Bebeimrat von Staubinger exläuterten Materien wirb nummegr baß ehelidge Büterrecht von Lanbgeridgtzrat Dr. Engelmann,

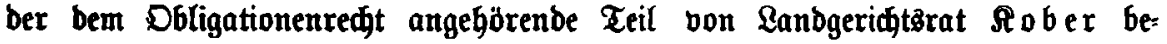
arbeitet; f. nadfftegenbe $\mathfrak{U}$ eber $\{$ idgt: 
Band 1: Einleitung und êtbifinitt 1 (ş 1-89) Brof. Dr. Th. Loemenfeld. शbjunitt 2-7 (\$s 90-240) . . . Prof. Dr. E. Riezler.

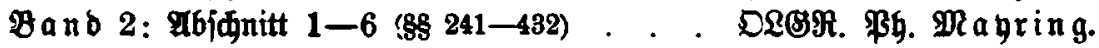

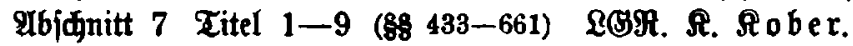

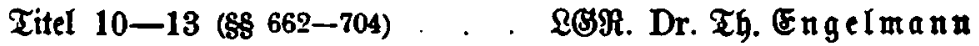

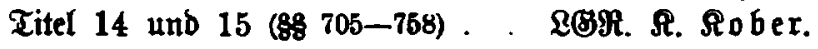
Titel 16-18 (\$8 769-778) . . . $28 \Re$. Dr. Th. Engelmann. Titel 19-23 (\$8 779-811). . . RER. R. Rober.

$\mathfrak{B a n b} 3$ Titel 24 und 25 (\$8 812-853) . $2 B \Re$. Dr. Th. Engel mann. Banb 4. . . . . . . . . . E\&. Dr. Th. Engelmann. Banb 5 . . . . . . . . . . . . . R9. Dr. Ff. Serzfelder. Band 6 . . . . . . . . . . . . D\&GM. $\mathfrak{S} \mathfrak{B a g n e r}$.

Die rebattionelle Reitung Des Bejamtwerts wirb bon Ranogeridtz:

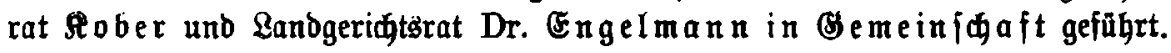

Die nunmehr jebem einzelnen Banbe beigegebenen $R$ egifter fowie baz alz Band 7 eriळeinende Befamtregifter find von $\mathfrak{A m t z r i d t e r ~} \Re$ eibel bearbeitet.

$\mathfrak{M}$ ü n®en， im Jamuar 1904.

\section{Sie Seransgeber.}

\section{Dorwort jur 3. und 4. Iluflage.}

Die zweite Auflage war fo hurze Beit nac ihrer Fertigftellung vergriffen,

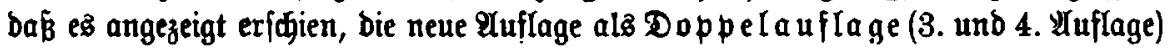
eriळeinen za lafien.

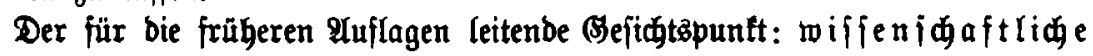
Durbbringung bes Stoffes bei forgfăltigfter Berüffichtigung

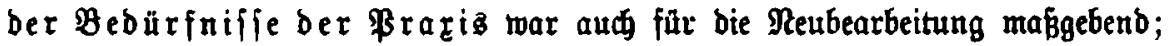

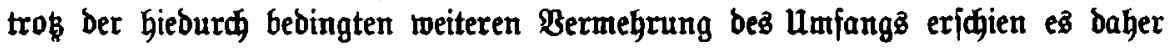
geboten, bie Grgebniffe ber Riteratur und Mechtfpredgung wie bishger mit tunlidifter BoMftänoigfeit $\mathfrak{z} \mathfrak{u}$ berüđfidðtigen.

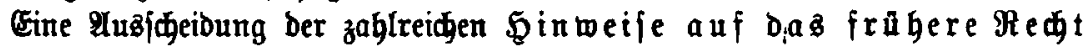

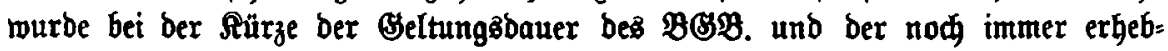

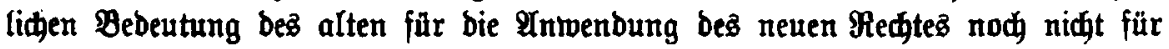
angezeigt erabitet. 